\title{
A revised linear ozone photochemistry parameterization for use in transport and general circulation models: multi-annual simulations
}

\author{
D. Cariolle $\mathrm{e}^{1,2}$ and $\mathbf{H}$. Teyssèdre ${ }^{3}$ \\ ${ }^{1}$ Météo-France, Toulouse, France \\ ${ }^{2}$ Centre Européen de Recherche et Formation Avancée en Calcul Scientifique, Toulouse, France \\ ${ }^{3}$ Centre National de Recherches Météorologiques, Météo-France, Toulouse, France
}

Received: 8 January 2007 - Published in Atmos. Chem. Phys. Discuss.: 31 January 2007

Revised: 16 April 2007 - Accepted: 18 April 2007 - Published: 2 May 2007

\begin{abstract}
This article describes the validation of a linear parameterization of the ozone photochemistry for use in upper tropospheric and stratospheric studies. The present work extends a previously developed scheme by improving the 2-D model used to derive the coefficients of the parameterization. The chemical reaction rates are updated from a compilation that includes recent laboratory work. Furthermore, the polar ozone destruction due to heterogeneous reactions at the surface of the polar stratospheric clouds is taken into account as a function of the stratospheric temperature and the total chlorine content.
\end{abstract}

Two versions of the parameterization are tested. The first one only requires the solution of a continuity equation for the time evolution of the ozone mixing ratio, the second one uses one additional equation for a cold tracer. The parameterization has been introduced into the chemical transport model MOCAGE. The model is integrated with wind and temperature fields from the ECMWF operational analyses over the period 2000-2004. Overall, the results from the two versions show a very good agreement between the modelled ozone distribution and the Total Ozone Mapping Spectrometer (TOMS) satellite data and the "in-situ" vertical soundings. During the course of the integration the model does not show any drift and the biases are generally small, of the order of $10 \%$. The model also reproduces fairly well the polar ozone variability, notably the formation of "ozone holes" in the Southern Hemisphere with amplitudes and a seasonal evolution that follow the dynamics and time evolution of the polar vortex.

The introduction of the cold tracer further improves the model simulation by allowing additional ozone destruction inside air masses exported from the high to the mid-latitudes, and by maintaining low ozone content inside the polar vortex

Correspondence to: D. Cariolle

(daniel.cariolle@cerfacs.fr) of the Southern Hemisphere over longer periods in spring time.

It is concluded that for the study of climate scenarios or the assimilation of ozone data, the present parameterization gives a valuable alternative to the introduction of detailed and computationally costly chemical schemes into general circulation models.

\section{Introduction}

The study of the climate evolution requires the implementation of global models coupling ocean, atmosphere and cryosphere. Due to the influence of radiatively active gases, atmospheric chemistry is now considered as an integral part of the climate system and the global models tend to include the main species and chemical cycles that allow the computation of their abundance (e.g. Eyring et al.,2006). This increases significantly the complexity of the code since several tens of species and hundreds of reactions are required to model adequately the chemical production and loss rates of the major active species. This is particularly true for ozone whose photochemistry encounters different regimes in the troposphere and the stratosphere, depending on the local thermodynamic state and on the possible activation of heterogeneous processes at the surface of aerosols and cloud particles. The result is that current state-of-the-art models (e.g. Chipperfield, 1999) that include a comprehensive description of the atmospheric chemistry require a large amount of computer time (several thousands hours of CPU) to run the multi decade simulations needed for climate studies. In addition, the build up of biases during the course of these long model integrations is very common since deficiencies in dynamics, temperature drifts, and limitations in the representation of the cloud cover can have a feed-back on photolysis and chemical rates and the distribution of trace species. For example, Eyring et al. (2006) reports climate model biases that can

Published by Copernicus GmbH on behalf of the European Geosciences Union. 
easily reach $5 \mathrm{~K}$ for the stratospheric temperature, and $20 \%$ for the ozone concentration.

The advantage of developing very simplified chemical schemes is to retain the major ingredients of the atmospheric chemistry while avoiding the complexity of the implementation of detailed chemical schemes.

For stratospheric and upper tropospheric ozone studies Cariolle and Déqué (1986), hereafter referred as CD86, where among the first to follow this approach. They developed a simple scheme by linearisation of the ozone continuity equation using a 2-D photochemical model. Their scheme has been introduced in many models, such as the ARPEGEClimat General Circulation Model (Déqué et al.,1994), and the ECMWF model (Andersson et al., 2003) for operational forecasts and the ERA40 reanalysis project (Oikonomou and O'Neill, 2006). The CD86 scheme has also been used within Chemical Transport Models (CTM) for the study of ozone trends (Hadjinicolaou et al., 2005; Jrrar et al., 2006) and within general circulation models (GCM) to study the ozoneclimate interactions (Braesicke et al., 2006; Pyle et al., 2006). Other linear schemes have been developed later, using climatological distributions of trace species to set the reference state (e.g. LINOZ, McLinden et al., 2000), or using a 2-D model to calculate the basic state and derivatives (e.g. Chem2D-OPP, McCormack et al., 2006).

Within ARPEGE-Climat, ozone is treated as a prognostic variable with sources and sinks evaluated using the CD86 linear scheme and is used for the radiative calculations. This allows one to study several types of ozone-climate interactions, for instance the impact on the ozone content of the global increase of $\mathrm{CO}_{2}$ (Mahfouf et al., 1994) or the temperature response to the localised ozone depletion over Antarctica (Cariolle et al. 1990). However, recent analysis of model outputs (M. Déqué, private communication) revealed a tendency of the ARPEGE-Climat GCM to be colder by $2-4 \mathrm{~K}$ than climatology in the lower stratosphere between 100 and $50 \mathrm{hPa}$, the ozone distribution in this altitude range being also lower than climatological data (Fortuin and Langematz, 1994; referenced FL hereafter) by about 10 to $15 \%$. At ECMWF, the CD86 ozone scheme has been used for assimilation of ozone observations and some of the coefficients derived by the 2D model had to be replaced by the FL dataset in order to remove biases in the lower stratosphere (Dethof and Holm, 2004). The CD86, Chem2D and LINOZ ozone parameterizations have also been compared in the context of satellite ozone data assimilation (Geer et al., 2007).

The initial development of the CD86 linear scheme dates from more than twenty years ago, and more accurate global ozone observations have been obtained, important chemical processes revealed, and some reaction rates have been reevaluated since then. In this context it is important to know if the linear approach followed so far could be improved in the light of our current knowledge, or if it is too restrictive compared to the accuracy reached by models that include a comprehensive treatment of the atmospheric chemistry. We show in the present article that it is still possible to obtain realistic ozone simulations using the linear model approach, and that the results compare favourably to satellite and in-situ observations.

The layout of this paper is as follows. In Sect. 2 we report on the latest updates of the linear scheme with various treatments for the ozone destruction by polar heterogeneous chemistry. In Sect. 3 we discuss the results obtained by the implementation of the linear scheme within a chemical transport model forced with operational meteorological analyses. Emphasis is placed on multi-annual simulations, on the ozone variability, and on the validation of the model outputs against total ozone column measurements from the TOMS instrument. The influence of the various methods used to take into account the ozone loss due to heterogeneous chemistry is also discussed. The final section summarizes the results.

\section{The linear ozone model}

\subsection{Basic formulation}

Following CD86 the ozone continuity equation is expanded into a Taylor series up to first order around the local value of the ozone mixing ratio, the temperature and the overhead ozone column:

$$
\begin{array}{r}
d r_{O_{3}} / d t=A_{1}+A_{2}\left(r_{O_{3}}-A_{3}\right)+A_{4}\left(T-A_{5}\right) \\
+A_{6}\left(\Sigma-A_{7}\right)+A_{8} r_{O_{3}}
\end{array}
$$

Where the $A_{i}$ terms are monthly averages calculated using the 2-D photochemical model MOBIDIC (Cariolle and Brard, 1984):

$$
\begin{aligned}
& A_{1}=(P-L): \text { Production and loss rate } \\
& A_{2}=\partial(P-L) / \partial r_{O_{3}} \\
& A_{3}=r_{\mathrm{O}_{3}}: \text { ozone mixing ratio } \\
& A_{4}=\partial(P-L) / \partial T \\
& A_{5}=T: \text { temperature } \\
& A_{6}=\partial(P-L) / \partial \Sigma \\
& A_{7}=\Sigma: \text { ozone column } \\
& A_{8}: \text { heterogeneous chemistry term, }
\end{aligned}
$$

whereas the other terms indicate the current 3-D values of the ozone mixing ratio $r_{O_{3}}$, the temperature $\mathrm{T}$, and the local overhead ozone column $\Sigma$, respectively.

Since our objective was to improve the accuracy of the parameterization, an important rewriting of the 2-D model was carried out. The chemistry scheme used in MOBIDIC includes the main gas-phase reactions driving the $\mathrm{NO}_{\mathrm{x}}, \mathrm{HO}_{\mathrm{x}}, \mathrm{ClO}_{\mathrm{x}}, \mathrm{BrO}_{\mathrm{x}}$ catalytic cycles, with 30 transported long-lived species, and 30 short-lived species computed using steady-state assumptions (see Table 1). The gas-phase chemical rates have been upgraded according to the recommendations of the JPL-2003-25 report. Since the heterogeneous processes involved in the polar stratospheric chemistry are highly non-linear and depend on the three-dimensional 
Table 1. Main characteristics of the MOBIDIC model.

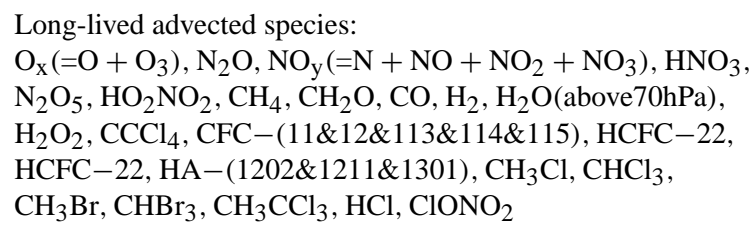

Model resolution:

60 vertical levels from ground to $0.1 \mathrm{hPa}$

64 latitudes, about $2.8^{\circ}$ latitudinal resolution

structure of the atmosphere, we decided not to include any heterogeneous chemistry in the 2-D model but, rather, to introduce an ad-hoc ozone destruction term, $A_{8}$, in Eq. (1) when conditions for polar stratospheric cloud (PSC) formation are met. The term $A_{8}$ was not introduced in the original CD86 formulation because the heterogeneous ozone destruction was not considered at that time. Two different formulations for evaluating the ozone loss rates are adopted in the present study, as described in the next section.

The dynamical and transport formulations of the 2-D model were also updated. The model is now integrated using a dynamical forcing from a transient scenario of the ARPEGE-Climat model which takes into account the evolution of trace gases having an impact on radiation and chemistry. In particular, the evolutions of $\mathrm{CO}_{2}, \mathrm{~N}_{2} \mathrm{O}, \mathrm{CH}_{4}, \mathrm{CFCs}$ and bromine compounds are taken into account for the period 1958-2000. All the necessary input required for the dynamical forcing used by the MOBIDIC model is obtained from 10 year averages of the ARPEGE-Climat outputs corresponding to the period 1990-2000. The MOBIDIC model adopts the residual meridional circulation formalism (Dunkerton, 1978) with the necessary heat and momentum fluxes derived from the ARPEGE-Climat outputs. Prather's advection scheme is used for transport of the long lived species (Prather, 1986). The overall characteristics of the MOBIDIC model are summarized in Table 1.

The partial derivatives appearing in Eq. (1) are obtained by perturbing the 2-D model fields by $\pm 10 \%$ for ozone mixing ratio and the ozone column, and by $\pm 10 \mathrm{~K}$ for temperature. This is done for each month and a set of zonal mean coefficients is obtained. To test the accuracy of the linearity of the system, we applied smaller and higher perturbations (up to $30 \%$ for ozone and $20 \mathrm{~K}$ for the temperature), and found very little deviations in the computated $A_{i}$. This means that the first order approximation used here is valid for a wide range of situations, as those generated by 3-D models. This

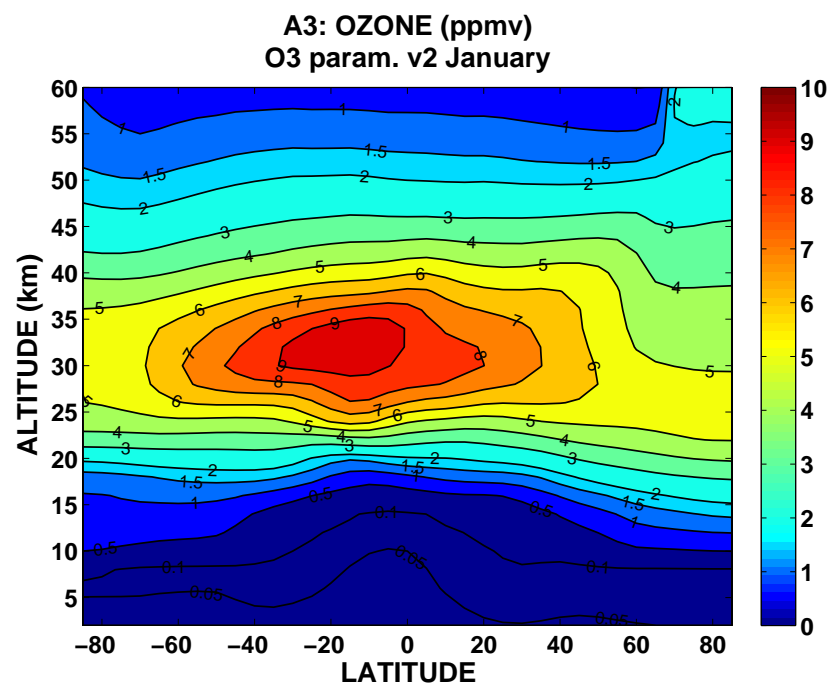

Fig. 1. Ozone background distribution (ppmv) as a function of altitude and latitude for the month of January.

result is consistent with the original findings of CD86 and those of McLinden et al. (2000), who followed a similar approach to derive the LINOZ scheme.

The background ozone distribution produced by the 2-D model and used within the parameterization (the $A_{3}$ term) is shown in Fig. 1 for the month of January. The main features seen in the observations are well reproduced with the ozone maximum value just above $10 \mathrm{ppmv}$ in the $30-35 \mathrm{~km}$ range centered at $20 \mathrm{~S}$ at that season. For all seasons, compared to the FL climatology and the HALOE ozone measurements (Morris et al., 2002), the local differences at low and midlatitudes are below $15 \%$ in the altitude range 15 to $40 \mathrm{~km}$, with larger differences with HALOE at the stratopause region, around $+40 \%$, and in the troposphere compared to the FL data. Compared to the CD86 version, the background ozone distribution is lower by about $20 \%$ above $40 \mathrm{~km}$, and larger by 1 to 2 ppmv between 20 and $30 \mathrm{~km}$. Overall, the present version gives a background ozone distribution in better agreement with satellite measurements.

The amplitude of the $A_{1}$ term in Eq. (1) gives an indication about regions of net photochemical ozone production or loss. The largest positive tendencies are found in the middle stratosphere at low and mid latitude between 10 and $35 \mathrm{~km}$ (Fig. 2). Ozone is produced by chemistry and removed by horizontal and vertical transport. Vertical transport at the equator plays an important role since the largest negative ozone tendencies are found above that region, vertical motions bring air with maximum ozone mixing ratios to altitudes where it is tightly controlled by photochemistry.

Thus, the effect of local unbalanced chemistry on the ozone distribution depends on the rate of transport and on the photochemical relaxation time $\tau$. The latter is obtained directly from the linearized scheme, $\tau=-1 / A_{2}$, and is shown 


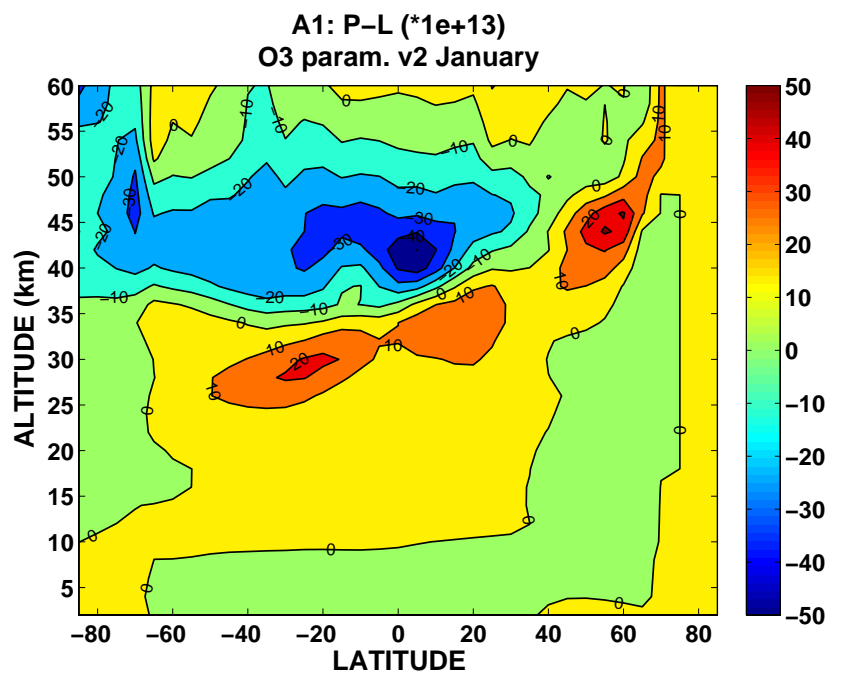

Fig. 2. Net photochemical rate $\left(10^{-7} \mathrm{ppmv} s^{-1}\right)$ as a function of altitude and latitude for the month of January.

in Fig. 3 for the month of January. Above $35 \mathrm{~km}$ in the daylight part of the atmosphere the relaxation time is short, below one week. It increases in the lower stratosphere due to the progressive absorption of UV radiation that controls the ozone production by photodissociation of molecular oxygen, and reaches a maximum of about 100 days at low latitudes near the tropopause. In the troposphere, due to the presence of the active HOx chemistry, the relaxation time decreases again to reach a minimum of about one week at the surface near the equator. Compared to CD86, the values of $\tau$ are very similar in the mid and upper stratosphere but slightly reduced in the lower stratosphere, a result of the updated chemical rates. Geer et al. (2007) analysed further the differences between the $A_{i}$ coefficients of the present version compared to CD86. In addition to the improvement in the ozone background distribution, the parameterization has now a much shorter radiation term $\left(A_{6}\right)$. The latter being obviously too large in the $\mathrm{CD} 86$ version.

At high latitudes beyond $60^{\circ}$ in the upper troposphere lower stratosphere the values of $\tau$ exceed 100 days for all seasons and there is a very weak control of the ozone concentration by gas-phase chemistry. In those regions ozone transport and ozone destroying mechanisms by heterogeneous chemistry (term $A_{8}$ ) play a major role. The next section describes how PSC chemistry is taken into account.

\subsection{Heterogeneous processes and ozone loss}

In the stratosphere heterogeneous reactions occur at the surface of sulphate aerosols and polar clouds. The latter are responsible for the largest part of the high latitude ozone destruction in winter and spring, and must be accounted for in the development of the present parameterization.

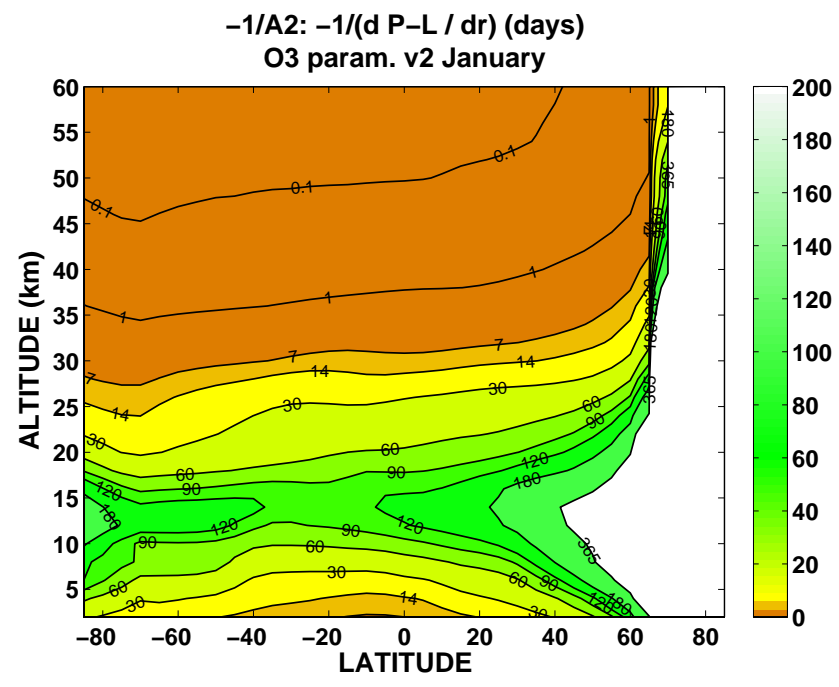

Fig. 3. Photochemical relaxation time (days) as a function of altitude and latitude for the month of January.

PSC chemistry operates via two main steps. During the first step, the composition of air masses that encountered temperatures below the threshold value for cloud formation is modified by the activation of chlorine species, the decrease in nitrogen oxide concentration, along with denitrification and dehydration (Solomon, 1999). This pre-conditioning phase is very efficient inside the Southern Hemisphere (SH) polar vortex during winter and spring due to the long duration of the polar night and the very low temperatures that prevail. In the Northern Hemisphere (NH) the same processes are somewhat less efficient because the polar vortex is more disturbed and the temperature is higher. In the simplified approach used here, the key parameter to be retained is the threshold temperature for polar cloud formation, about $195 \mathrm{~K}$ for NAT particles in the conditions of humidity and pressure of the lower stratosphere.

After the preconditioning phase the processed air masses are prone to ozone destruction provided that they experience sunlight, and that their chlorine content is large enough. The most efficient ozone destroying catalytic cycle involves the formation of the chlorine monoxide dimer $\mathrm{Cl}_{2} \mathrm{O}_{2}$, the concentration of which is close to the total chlorine content $\left(\mathrm{Cl}_{\mathrm{X}}\right)$ if the air masses have been fully activated. In that case the ozone destruction rate is a quadratic function of the $\mathrm{Cl}_{\mathrm{x}}$ concentration and is sensitive to the temperature via the rate of $\mathrm{Cl}_{2} \mathrm{O}_{2}$ thermal decomposition. An other destroying cycle involving bromine (via the reaction $\mathrm{BrO}+\mathrm{ClO}$ ) can play a role in the polar ozone destruction with a rate proportional to the total bromine and chlorine contents. Therefore, adopting a quadratic rather than a linear function of the $\mathrm{Cl}_{\mathrm{x}}$ concentration for the total ozone destruction rate should be considered as an upper limit. 


\subsubsection{Parameterization based on the local temperature}

It is of course not possible to include the details of all the processes described above in the adopted framework. So, two versions of the parameterization have been developed. The first one (hereafter referred as v2a) retains an additional term $A_{8}=-K_{\text {het }}$ in Eq. (1) for ozone destruction when the temperature is low enough and the sun is over the horizon:

$K_{\text {het }}=1 / \tau_{0}\left(\mathrm{Cl}_{\mathrm{x}} / 2 \mathrm{ppbv}\right)^{2}$

with $1 / \tau_{0}=1 /(8$ days $)$ for daytime conditions when $T \leq 195 \mathrm{~K}$, and $1 / \tau_{0}=0$ otherwise.

This parameterization assumes that preconditioning and destruction processes are working simultaneously and stop as soon as the temperature is high enough for the PSCs to evaporate. The destruction rate is a quadratic function of total chlorine mixing ratio and is set to 8 days for $2 \mathrm{ppbv}$ of total chlorine. The distribution of the total chlorine, $\mathrm{Cl}_{\mathrm{x}}$, is calculated by the MOBIDIC model and monthly mean $A_{8}$ terms are produced.

The total chlorine content reaches $3.6 \mathrm{ppbv}$ in the upper stratosphere. It corresponds to the year 2000 situation. Given the gradual return of sunlight at high latitudes, the effective destruction time of ozone in the SH spring vortex is of the order of 15 days, which is consistent with the observed evolution of the vertical profiles from ozone soundings (Hofmann et al., 1994). A similar rate was adopted with success by Cariolle et al. (1990) in their simulation of the Antarctic ozone hole.

Within MOBIDIC the introduction of the $A_{8}$ term, in addition to the tendencies from the gas phase chemistry in the ozone continuity equation, leads to an ozone distribution that compares well with observations. For instance the seasonal evolution of the total ozone column (Fig. 4) is in rather good agreement with the TOMS data (version 8 algorithm available from http://toms.gsfc.nasa.gov/). The ozone values are below 200 Dobson units (DU) in the vortex in September, whereas the equatorial minimum is in the 255-280 range. Due to a rather early polar SH warming from the ARPEGEClimat forcing, at the end of September, the ozone destruction is limited in time. Section 3 reports chemical transport model (CTM) calculations with a larger ozone destruction that can extend to early November depending on the dynamical and temperature forcing.

The high latitude $\mathrm{NH}$ spring maximum is just over $480 \mathrm{DU}$, a value that compares well with TOMS data, although the adopted residual circulation tends to confine the ozone maximum over the pole and does not bring enough ozone at mid latitudes. This shortcoming is not seen in the ARPEGE-Climat ozone simulations and appears as a limitation of the residual circulation approach.

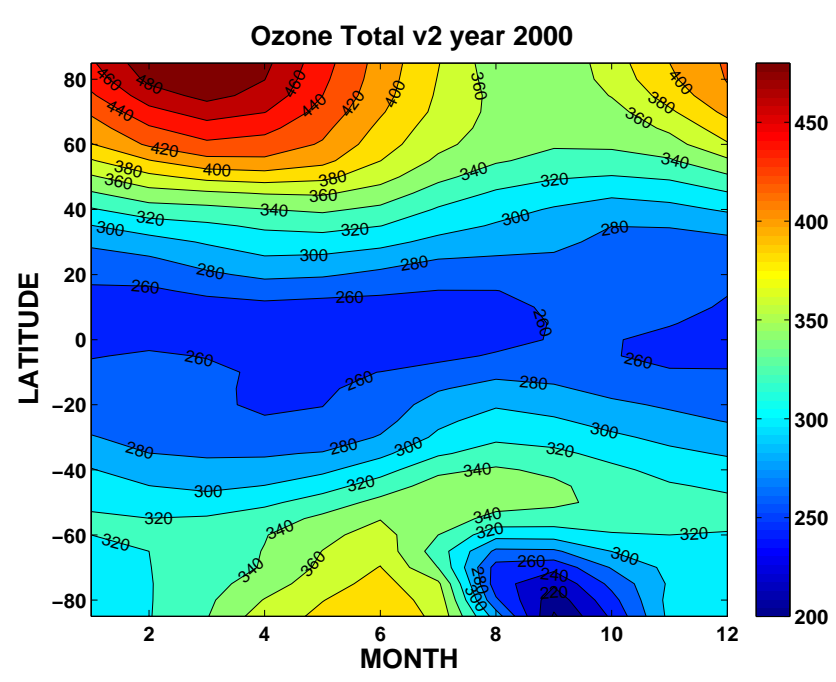

Fig. 4. Total ozone column from the MOBIDIC model generating the $\mathrm{v} 2 \mathrm{a}$ of the ozone linear scheme. 2.2.2 Parameterization based on the distribution of a cold
tracer

One of the major shortcomings on the way heterogeneous processes are taken into account in the scheme described above is the assumption that pre-conditioning and ozone destruction phases are simultaneous. The pre-conditioning phase depends indeed on the history of the air masses. In the SH the air within the core of the polar vortex stays below the temperature for PSCs formation from June to October, whereas in the $\mathrm{NH}$ the dynamics is usually much more perturbed in winter and the pre-conditioning periods can be quite sporadic. One way to address this issue is to record the air masses history by means of a tracer whose concentration depends on the temperature encountered. To this end, we define a "cold tracer" whose mixing ratio, $\delta$, is varying between 0 and 1 . The value of $\delta$ increases exponentially to the asymptotic value of 1 on a time scale $\tau_{1}$ when the air temperature is below the threshold value for polar cloud formation. This accounts for the pre-conditioning phase where chlorine is activated and the air masses are prone to ozone destruction. The deactivation of air masses can then operate either by mixing with inactivated air masses, or by the PSC's evaporation and the return of $\mathrm{NO}_{\mathrm{x}}$ species in the chemical system. In the last case, the ozone-destroying cycles involving $\mathrm{ClO}$ and $\mathrm{Cl}_{2} \mathrm{O}_{2}$ become inefficient due to their competition with $\mathrm{ClONO}_{2}$ formation and the $\mathrm{ClO}+\mathrm{NO} \rightarrow \mathrm{Cl}+\mathrm{NO}_{2}$ reaction. The return of the $\mathrm{NO}_{\mathrm{x}}$ radicals depends on the concentration of the reservoir species $\mathrm{N}_{2} \mathrm{O}_{5}$ or $\mathrm{HNO}_{3}$. Satellite observations (Mengistu Tsidu et al., 2004) show that the concentration of $\mathrm{N}_{2} \mathrm{O}_{5}$ is quite low in the winter polar vortices due to its conversion to $\mathrm{HNO}_{3}$ by heterogeneous reactions on aerosols and PSCs. Hence, after the evaporation of the PSCs the major reservoir species is in the form of $\mathrm{HNO}_{3}$. 


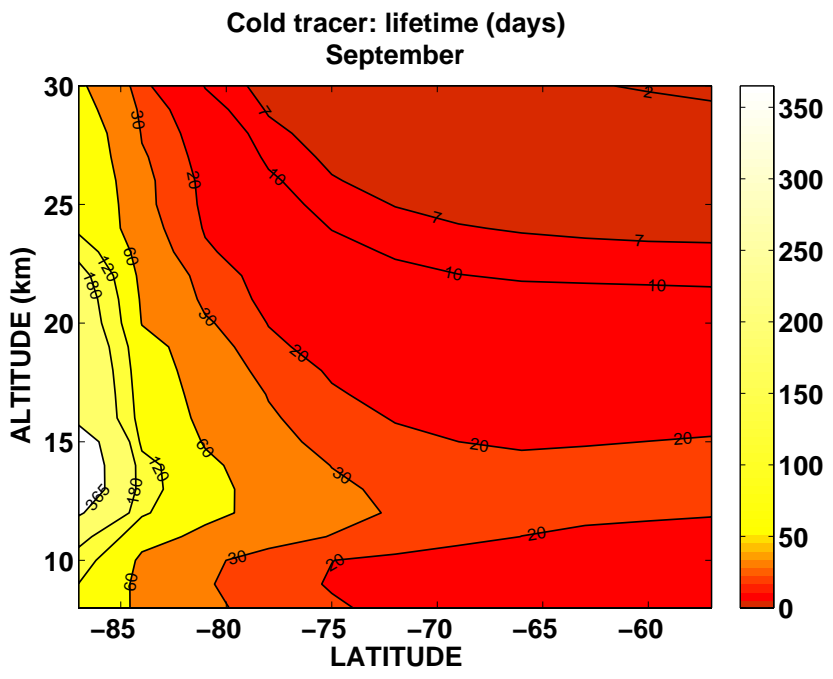

Fig. 5. Chemical lifetime for $\mathrm{HNO}_{3}$ in September. This lifetime is used to compute the decay rate of the concentration of the cold tracer (see Sect. 2).

The chlorine deactivation by $\mathrm{NO}_{\mathrm{x}}$ increase occurs on a time scale $\tau_{2}$, and since the source of $\mathrm{NO}_{\mathrm{x}}$ comes from the $\mathrm{HNO}_{3}$ destruction we assumed $\tau_{2}$ equal to the lifetime of $\mathrm{HNO}_{3}$, taking into account photodissociation and destruction by reaction with the $\mathrm{OH}$ radical.

One shortcoming of this approach is that it assumes that there is always enough $\mathrm{HNO}_{3}$ to restore the $\mathrm{NO}_{\mathrm{x}}$ species; about 2 ppbv are required. In case of highly denitrificated air masses due to ice particle sedimentation, there would not be enough $\mathrm{NO}_{\mathrm{x}}$ formation from $\mathrm{HNO}_{3}$ destruction to deactivate the chlorine radicals. In that case the present scheme could underestimate the occurrence of processed air masses and the ozone depletion. Results from the next sections show that in practice this seems not to be the case because in highly processed air masses ozone depletion rates are larger than calculated $\mathrm{NO}_{\mathrm{x}}$ restoring rates, so significant ozone depletion occurs before the cold tracer concentration is relaxed to 0 .

Hence, the continuity equation for the tracer mixing ratio $\delta$ reads:

$d \delta / d t=\left(1 / \tau_{1}\right) \times(1-\delta)-\left(1 / \tau_{2}\right) \times \delta$

with $1 / \tau_{1}=0$ and $1 / \tau_{2}=$ loss rate of $\mathrm{HNO}_{3}$ if $T>195 \mathrm{~K}$, and with $1 / \tau_{1}=6 \mathrm{~h}$ and $1 / \tau_{2}=0$ if $T<195 \mathrm{~K}$.

With this scheme the concentration of the cold tracer mimics the behaviour of the air masses. The $\delta$ values are close to unity for freshly processed air, or more aged processed air that has remained in the dark without significant mixing with unprocessed air. The values are close to zero for air not having being in contact with PSCs, or processed air that has been mixed with unprocessed air or exposed to sufficient sunlight for NOx restoring and chlorine deactivation.

For the numerical computations referred thereafter $\tau_{1}$ was set to $6 \mathrm{~h}$, a typical time scale for chlorine activation, and $\tau_{2}$ was calculated using the MOBIDIC model. Figure 5 shows that the rate $\tau_{2}$ is quite long in the lower stratosphere in winter/spring, between 2 to 4 weeks at high and mid-latitudes. It means that processed air can travel a long way from the vortex edge with still a large potential for ozone destruction. Hadjinicolaou et al. (1997), Hadjinicolaou and Pyle (2004) used the CD86 scheme with a similar cold tracer formulation to account for polar ozone destruction. However, the lifetime that they adopted for the tracer was substantially shorter, i.e. 5 days in the $\mathrm{NH}$ and 10 days in the $\mathrm{SH}$. We discuss below the need for the ozone destroying rate to be a function of temperature. This is important because the air masses extracted from the vortex will warm by several tens of degrees when transported to lower latitudes. With our formulation (Eq. 4), an increase of the cold tracer temperature from 195 to $220 \mathrm{~K}$ would decrease the destruction rate by $40 \%$ and bring the effective destruction rate close to what is obtained with a tracer whose lifetime is between 1.2 to 2.5 weeks without temperature dependance for ozone destruction. Consequently, the two formulations are not so different as they may appear. Though ours is based on a more detailed analysis of the chemical processes at play.

Using the cold tracer concentration the $A_{8}$ term of Eq. (1) now takes the form:

$A_{8}=-K_{\text {het }} \delta(195 / T)^{4.5}$

with $K_{\text {het }}$ given by Eq. (2), and with $1 / \tau_{0}=1 /(8$ days) for daytime conditions without temperature dependence.

Compared to the v2a formulation, the ozone loss can now occur in processed air without the presence of PSCs and in remote regions, away from the location where it has been activated. However, even in highly processed air, the destruction rate must now depend on temperature since a temperature increase would decrease the $\mathrm{Cl}_{2} \mathrm{O}_{2}$ concentration and offset the ozone destroying catalytic cycles. This effect is introduced via the term $(195 / T)^{4.5}$ (see Eq. 4.), i.e. the temperature dependance of the reaction rate for $\mathrm{Cl}_{2} \mathrm{O}_{2}$ thermal decomposition. This effect should be important during the export of the polar processed air masses to the mid-latitudes. The heating by solar UV absorption increases and the air masses warm, so that thermal decomposition of $\mathrm{Cl}_{2} \mathrm{O}_{2}$ becomes significant. Additional heating also occurs with mixing of polar air with mid-latitude air. As already discussed, this reduces the effective duration of ozone destruction during air masses export.

Therefore, the second version of the ozone parameterization (hereafter referred as v $2 b$ ) is obtained by integration of two continuity equations, the first one for ozone (Eq. 1 with the A8 term given by Eq. 4) and the second one for the cold tracer (Eq. 3). Compared to v2a where only Eq. (1) is solved, the required computing time increases, but the representation of the ozone destruction parametrization follows more closely our current understanding of the most important processes. Model simulations reported in Sect. 3 show that the timing for the SH polar ozone depletion is better reproduced 
by the v $2 \mathrm{~b}$ with the cold tracer than the v2a formulation, and that at mid-latitudes significant ozone reductions are induced by the cold tracer transport and subsequent ozone destruction.

\section{Implementation of the ozone scheme in a Chemical Transport Model}

3.1 Multi-annual simulations with dynamical forcing from ECMWF operational analyses

The v2a parameterization has been implemented within the MOCAGE CTM (Josse et al., 2004) and a 5 year simulation has been performed forced by the ECMWF operational analyses for winds, humidity, temperature and surface pressure. The simulation covers the period from January 2000 to the end of 2004. The CTM used the same vertical coordinate and resolution as the ECMWF model, with 60 levels and a horizontal resolution corresponding to a spectral $\mathrm{T} 42$ grid (about $2.8^{\circ}$ resolution). The ozone advection is performed with a semi-lagrangian scheme without any diffusion or parameterised transport for sub-grid processes. Emphasis is therefore placed on the stratospheric and upper tropospheric ozone distributions.

Figure 6 shows the simulation of the total ozone column over the period 2001-2004, after one year of spin up. Overall the model reproduces the main features of the TOMS observations with the equatorial minimum in the 230-260 DU range, the maximum in spring over the high northern latitudes, the belt of ozone maxima in the southern mid-latitudes, and the "ozone hole" development at polar latitudes in the SH.

At low latitudes the seasonal evolution of the ozone content is well captured, but with a tendency to underestimate the meridional amplitude of the equatorial minimum that forms a dipole structure in the TOMS data. This structure is particularly marked in 2002 and 2004. For those years the model underestimates the minimum that develops from April to June at $20^{\circ} \mathrm{S}$, and produces an ozone minimum at $20^{\circ} \mathrm{N}$ in November-December, about one month earlier than observed. The model behaviour is the response of the meridional displacements of the maximum of the vertical velocities associated with the upward branch of the Hadley circulation. In the IFS model that generates the analyses, the large scale vertical velocities in the upper troposphere are forced by the equatorial convection. The convective processes are not directly resolved within the ECMWF model and are parameterized. The CTM results might reveal some weakness in the position and/or intensity of the convective processes.

In the SH mid-latitudes the model simulation compares well with the satellite data, with a progressive build up of a belt of ozone maxima during winter and a relative minimum during February-March. The absolute ozone amounts are however overestimated by about $20-40 \mathrm{DU}$ throughout the year. At high southern latitudes the polar ozone depletion in spring is well captured by the parameterization. The ozone decrease within the polar vortex starts with the return of the sunlight and reaches a minimum in the range 100-120 DU in late September, in good agreement with observations. To evaluate the effect of the heterogeneous destruction on the ozone distribution we have integrated the model for the year 2001 without the $A_{8}$ term. The total ozone column inside the vortex remains in the range $280-320$ DU from June to September, and the belt of ozone maximum at mid-latitudes in the range 380-420 DU, about $40 \mathrm{DU}$ larger than the simulation with the full implementation of the parameterization. It means that significant ozone depletion is exported from the polar to the mid-latitudes, and this process is essential for a correct simulation of the SH ozone distribution.

The year-to-year variability is also well reproduced and follows the variations of the temperatures inside the vortex. In particular, the warmings of September 2002 and October 2004 drive an ozone increase over the pole that is well captured. Section 3.3 goes through the details of the model simulation for the perturbed 2002 and the rather unperturbed 2001 spring periods. The major weakness of the simulation which appears almost every year, is linked to an early recovery of the ozone content inside the vortex in OctoberNovember when the temperature increases over the chosen $195 \mathrm{~K}$ threshold for PSC formation. The recovery is too early by about 2 weeks, Sect. 3.4 shows that this shortcoming is improved when the $\mathrm{v} 2 \mathrm{~b}$ parameterization with cold tracer is used.

In the NH mid and high latitudes the model catches the main features of the seasonal variations, with the build up of ozone maxima in March-April followed by a decrease up to October. The year to year variability is also reproduced with for example a larger ozone amount in 2001 than for the other years. However, compared to the TOMS data, the model overestimates the polar ozone by about $60-80 \mathrm{DU}$ in Spring and Autumn. Comparison of the ozone vertical profiles with sounding data shows that ozone is overestimated in the lower stratosphere-upper troposphere between 200 and $70 \mathrm{hPa}$. The overestimation peaks at $150 \mathrm{hPa}$ and can reach a factor two in the local ozone concentration. This could be due to insufficient parameterised PSC's ozone depletion in winter and spring, or excessive ozone transport from the midlatitudes by the ECMWF wind analyses. Section 3.4 shows that adopting the parameterization with the cold tracer formulation improves the simulation without however removing completely the model overestimation. This overestimation is not observed with the MOBIDIC model which is driven by the meridional mean circulation from the ARPEGE-Climat GCM (see Fig. 4). It must be therefore attributed to the equator to pole circulation forced by the ECMWF analyses. The next section describes an experiment which clearly shows that the poleward ozone transport is larger than the one obtained from the GCM. 

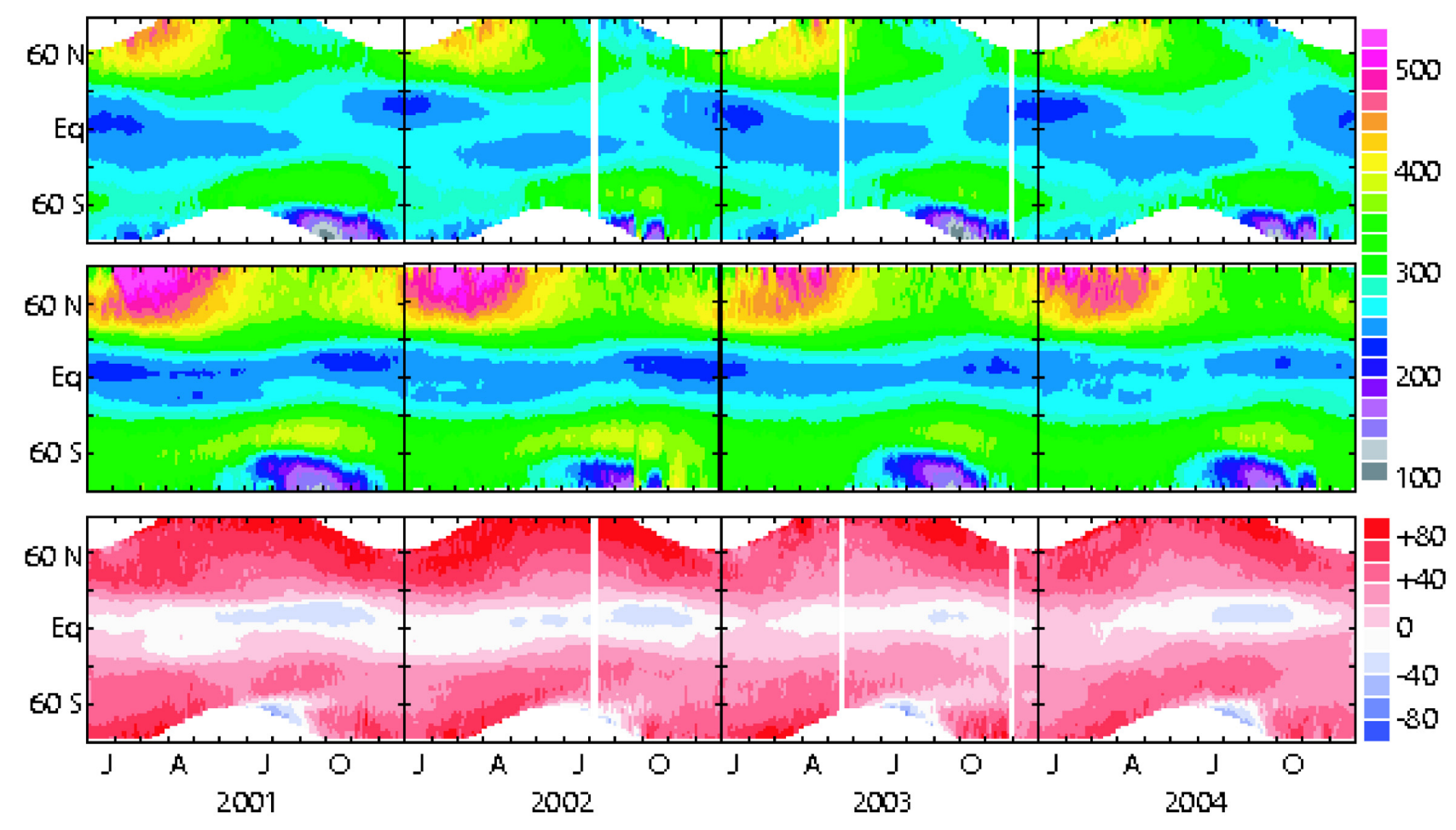

Fig. 6. Total ozone distributions as a function of latitude and time over the period 2001-2004. Upper panel: TOMS data; lower panel: MOCAGE results using the v2a parameterization; lower panel: difference between model and TOMS ozone fields (DU).

\subsection{Consistency test for the large scale meridional circula- tion}

Our linearised ozone scheme is not directly linked to a specified transport model in the sense that the partial derivatives in Eq. (1) are calculated by only solving the chemical equations within the model. However, on average, the term $A_{1}$ must be balanced by the divergence of all the transport fluxes: $A_{1}=-\operatorname{Div}_{2 D}\left(\operatorname{Flux}\left(A_{3}\right)\right)$. For the 2-D model this is valid for yearly averages but it also holds approximately at any time because the net chemical ozone tendency and the divergence of the transport fluxes are almost balanced in regions where the ozone lifetime is short enough, below about one month. It is therefore possible to obtain an indirect measure of the ozone changes brought by the meridional circulation forced by the ECMWF analyses and compare it to the one used by the 2-D model. To that end, we have conducted an experiment where ozone is advected by modified wind fields $\left(u^{*}, v^{*}, w^{*}\right)$ where a large part of the zonal mean components $\left(<v>,\langle w>)\right.$ is removed. The $A_{1}$ term in Eq. (1) is modified accordingly. We obtain:

$$
\begin{aligned}
u^{*} & =u \\
v^{*} & =v-<v>. f(\theta) \\
w^{*} & =w-<w>. f(\theta) \\
A_{1}^{*} & =A_{1} .(1-f(\theta))
\end{aligned}
$$

Where $f(\theta)$ is a function of the latitude $\theta$ that varies from 1 at the equator to 0 near the poles where the zonal averages are defined by too few points. We chose $f(\theta)=\cos (\theta)^{8}$ in order to use the modified wind field for latitudes lower than $50^{\circ}$. It leads to a restricted implementation of the ozone parameterization where at each time step the divergence of the ozone fluxes from the zonal averaged meridional circulation is assumed to balance the same term evaluated from the 2-D model. Compared to the simulation with the unmodified winds, Fig. 7 shows that the total ozone column distribution obtained with this method for the year 2001 gives more ozone at the equator and much less at mid and high latitudes in the Northern Hemisphere. It is in better agreement with both MOBIDIC outputs and the TOMS data. This demonstrates that the equator-to-pole meridional circulation given by the ECMWF analyses is larger than the corresponding circulation given by the ARPEGE-Climat model. It accounts for an overestimation of the ozone columns by 40 to $60 \mathrm{DU}$ during the spring maximum at high NH latitudes. Smaller differences, between 20 and 40 DU, are observed in the SH.

The tendency for excessive equator to pole circulation intensity by the ECMWF analyses has been already diagnosed by analysis of satellite and soundings ozone data (de Laat et al., 2007), and with the calculation of stratospheric "age of air" (Bregman et al., 2006). The age of air is defined as the time that a stratospheric air mass has been out of contact with 
the troposphere. From observed long lived tracer distribution (e.g. $\mathrm{CO}_{2}, \mathrm{SF}_{6}$ ) it is possible to infer the age of air in the stratosphere (Boering et al., 1996). At $50 \mathrm{hPa}$, current determinations give values ranging from 1 year at the equator to about 4 years at the poles. Using the ECMWF analyses we have computed the age of air distribution. This has been done by integrating the MOCAGE CTM over 20 years forced with the analyses from the years 2000 and 2001. As expected, we found that the age of air is quite short, values of 6 months at the equator and 2 years over the poles are computed for the $50 \mathrm{hPa}$ level. A similar calculation using a forcing from the Arpege/Climat model gives ages of air ranging from 1 year at the equator to about 3.5 years at the poles for the same level. Those results are fully consistent with the calculations reported above with the implementation of the restricted $\mathrm{v} 2 \mathrm{a}$ ozone parameterization. Thus, for the period under study, the operational ECMWF analyses have an excessive meridional circulation that causes an overestimation of the high latitude ozone column by at least 40-60 DU in the Northern Hemisphere. In the SH the age of air distribution is also too low with the ECMWF analyses, and the meridional ozone transport is expected to be equally overestimated. However the impact on the ozone distribution of this excessive transport appears mostly limited to the latitude band $40-60^{\circ}$, outside the polar vortex, where the ozone column is overestimated by about $20-40 \mathrm{DU}$.

Inside the vortex, the ozone evolution is driven by the fast heterogeneous chemical destruction and appears not so sensitive to the meridional circulation intensity.

\subsection{Polar vortex variability and ozone distribution}

The results described above show that the ozone parameterization v2a combined with the forcing by the ECMWF operational analyses is able to capture the large scale ozone distribution and its inter-annual variability. It is however important to check if the system can also reproduce in detail the time evolution of ozone during episodes presenting rapid change due to active dynamics or with activation of ozone destroying processes.

To explore this, we first focus on the comparison of the model results with TOMS data during the years 2001 and 2002 that presented a very different behaviour of the SH polar vortex and the associated ozone distribution. During 2001 the polar vortex was mostly unperturbed for the whole winter-spring and the "ozone hole" built up progressively in September, and lasted until mid-November. Figure 8 shows the TOMS map for 15 September. At that date the ozone content is minimum inside the vortex, below $150 \mathrm{DU}$, and the vortex boundary marks the transition from undepleted to ozone depleted air masses. The model distribution for the same date (Fig. 8) shows very good agreement with the satellite data. The total ozone columns within the vortex are in the 140-180 DU range, and the belt of maxima at mid-latitudes is well reproduced in shape and intensity, with a slight over-

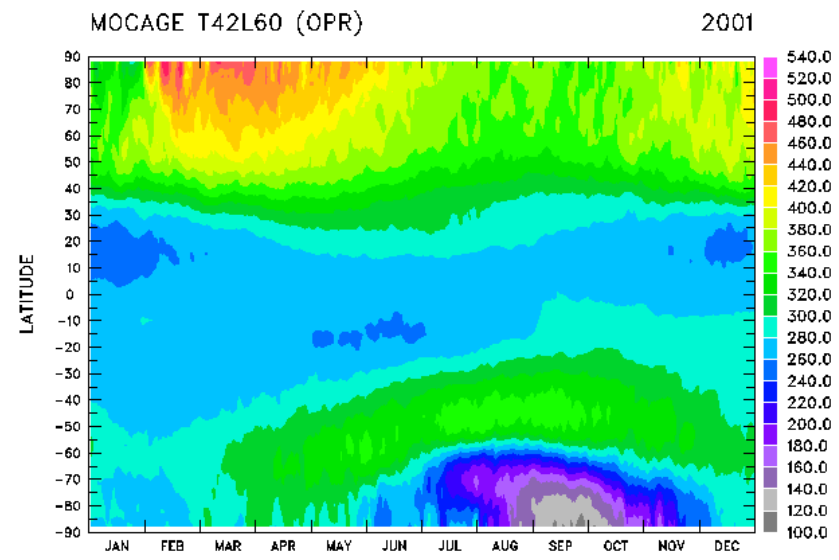

Fig. 7. Total ozone distributions as a function of latitude and time for the year 2001 produced by using the "restricted" implementation of the v2a parameterization (see Sect. 3.2).

estimation of the ozone column by $20 \mathrm{DU}$. The ozone gradient at the edge of the vortex is under-evaluated, but this is due to the limited CTM horizontal resolution, about $2.8^{\circ}$, that cannot handle the sharp vortex boundaries.

One month later the same characteristics for the dynamics hold (Fig. 9), but there is a tendency for the model to produce a polar ozone minimum that "shrinks" too rapidly compared to TOMS data. The model resolution appears not to be the cause of this excessive ozone recovery in the centre of the vortex. It is rather due to the turn off of the ozone destruction by the heterogeneous term of the parameterization, following the warming of the air masses and their temperature rise above the $195 \mathrm{~K}$ threshold. In the next section we show that this shortcoming is improved by the version $v 2 b$ of the parameterization that uses the cold tracer formulation.

Compared to 2001, during the winter-spring of 2002 the polar vortex was much more disturbed. It was elongated most of the time in August, and eventually split into two distinct vortices during the second half of September. This behaviour with such a large planetary wave 2 activity was very peculiar (Simmons et al., 2005) and the consequences on the distributions of minor species in the stratosphere have been reported in several studies (e.g. Ricaud et al., 2005). Figure 10 shows the TOMS map on 25 September with the two ozone minima associated to the split vortex. The model simulation on the same day (Fig. 10) compares again very well with the observation, the differences in the total ozone content being in the range of $20 \mathrm{DU}$. This illustrates how efficient the ozone parameterization is when forced by high quality atmospheric analyses. After more than 1.5 year of simulation the biases with the observations on the global scale are minimal, and the simulated ozone distribution compares very favourably to the models using a detailed chemical scheme (Feng et al., 2006). 
TOTAL OZONE (DU) EP/TOMS level 8

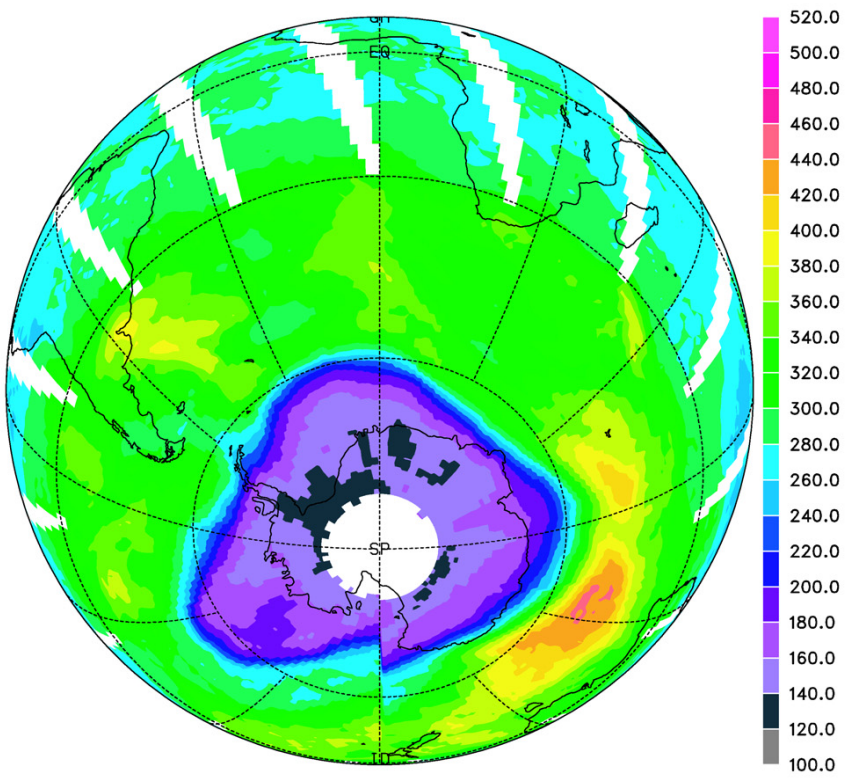

$2001 / 09 / 15$

\section{MOCAGE T42L60 version 2}

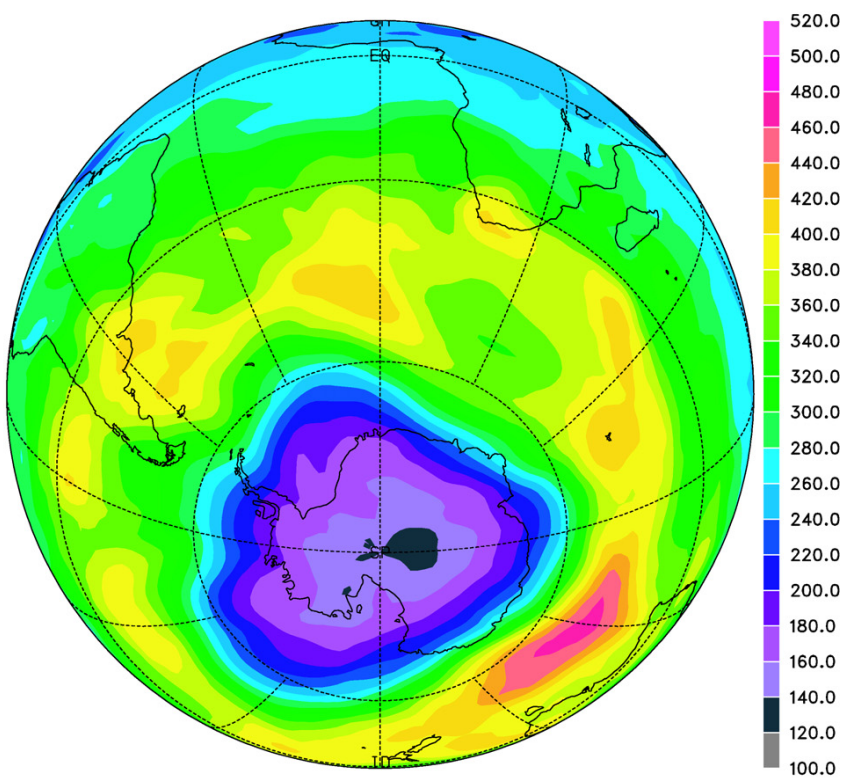

Dobson Units

Fig. 8. Total ozone column for 15 September 2001 from the TOMS data (left) and from the MOCAGE simulation using v2.a parameterization (right).

TOTAL OZONE (DU)

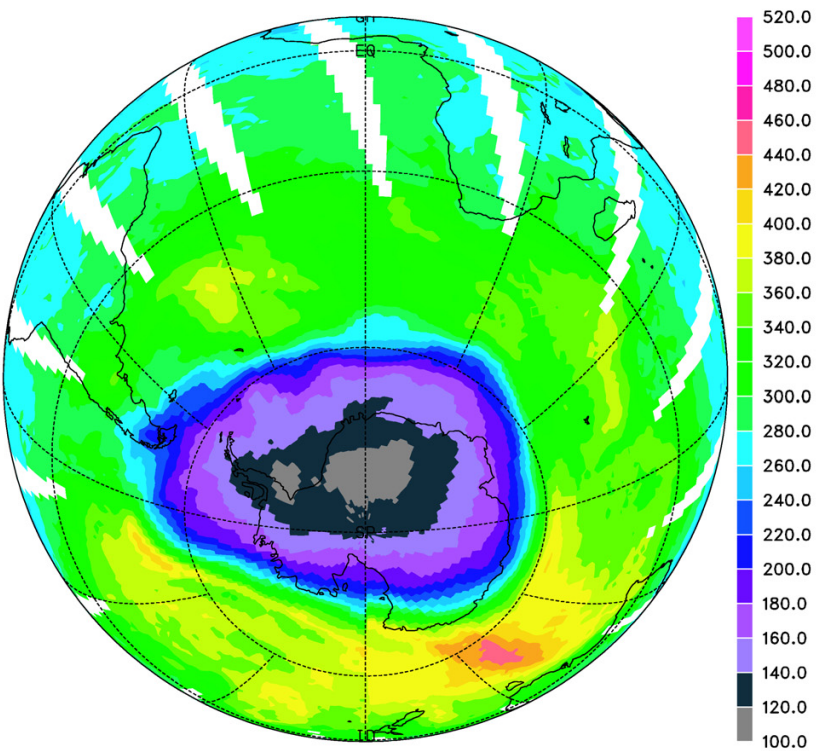

$2001 / 10 / 15$
MOCAGE T42L60 version 2

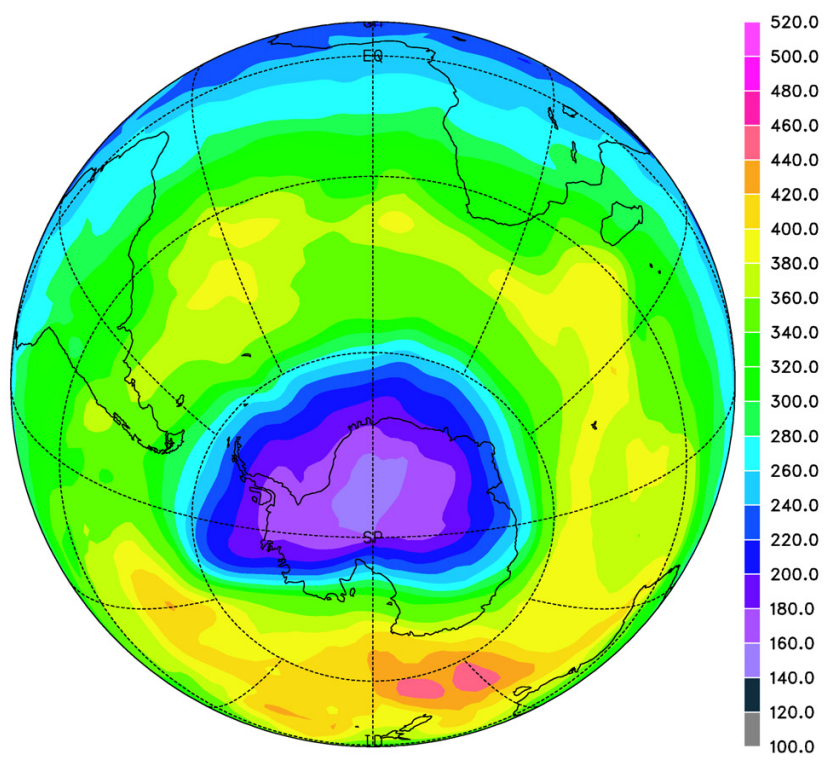

Dobson Units

Fig. 9. Total ozone column for 15 October 2001 from the TOMS data (left) and from the MOCAGE simulation using v2.a parameterization (right). 
TOTAL OZONE (DU) EP/TOMS level 8

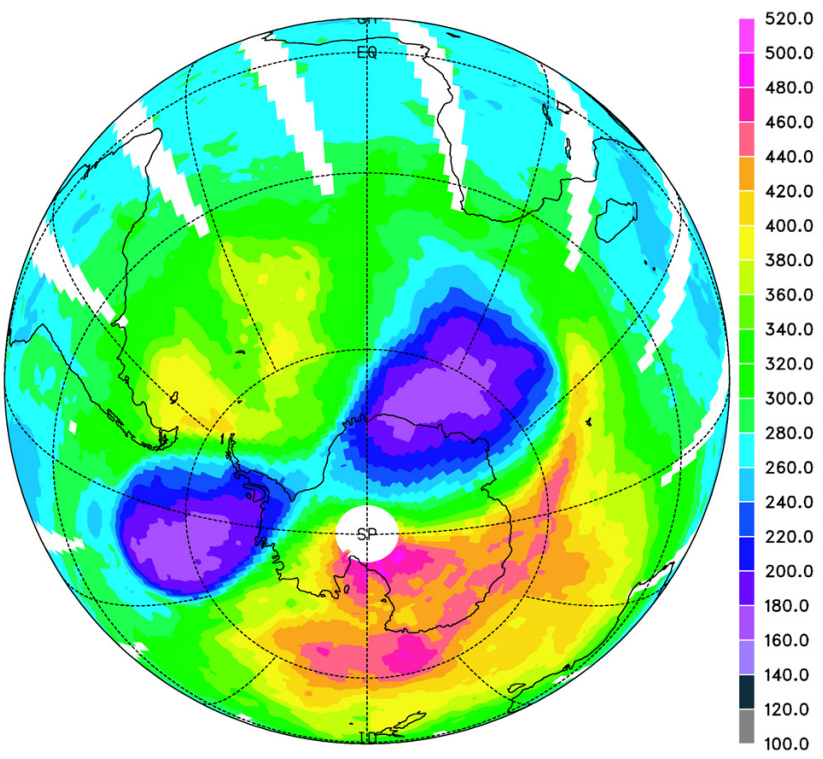

$2002 / 09 / 25$
MOCAGE T42L6O version 2

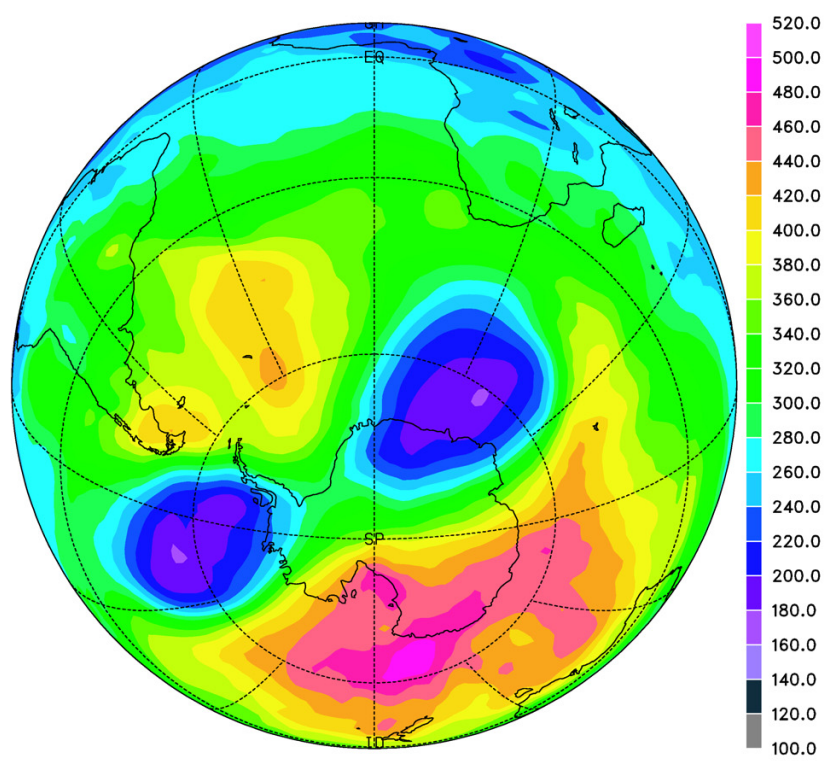

Dobson Units

Fig. 10. Total ozone column for 25 September 2002 from the TOMS data (left) and from the MOCAGE simulation using v2.a parameterization (right).

\subsection{Cold tracer and mid and high latitude ozone destruction}

In this last set of simulations the $\mathrm{v} 2 \mathrm{~b}$ ozone parameterization is implemented with the cold tracer as described in Sect. 2.2.2. The 5 year simulation 2000-2004 is repeated and the analysis focuses on the year 2001 for the winter-spring seasons during which the polar temperatures are low enough to form PSCs in both hemispheres.

Figure 11 shows the distribution at $50 \mathrm{hPa}$ of the cold tracer at the beginning of October in the SH. As expected, the value of the tracer is close to 1 in the core of the vortex where air masses have been processed, and strong tracer gradients mark the transition from inside to outer vortex unprocessed air masses. Although the vortex was not much disturbed during that period, tongues of vortex air are extracted to the midlatitudes. One of these is well marked in the south American sector, with tracer values in the range 0.05 to 0.15 . Another one is also visible spanning from New-Zealand to South Africa with tracer values around 0.1. This means that in those sectors ozone depletion is possible at a rate 6 to 10 times slower than in the vortex core, provided that the temperature is cold enough (see Eq. 4). This typical situation with slow erosion of the vortex holds until the final warming and the vortex breakdown.

The impact of using the $v 2 b$ parameterization on the ozone distribution is twofold. First, at polar latitudes the ozone decrease in September-October is maintained for about 15 more days than when using the v2a formulation (Fig. 12). This is because the ozone depletion inside the vortex can last

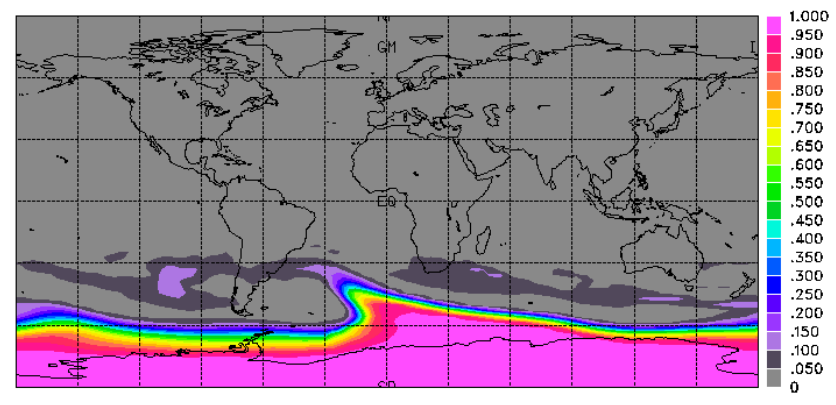

$2001 / 10 / 0100$

$50 \mathrm{hPa}$

Fig. 11. Distribution of the cold tracer mixing ratio for the 1 October 2001 .

longer due to high values of the tracer and still cold enough temperature. As a result, the ozone minimum inside the vortex in October is about 20 DU lower using v2b than with v2a. As discussed in the previous section this brings the model simulations in better agreement with observations. In both formulations of the parameterization the ozone destruction by the PSC chemistry is activated as the sun comes back, as soon as the solar zenith angle is lower than $90^{\circ}$. To evaluate the influence of possible delay in the ozone destruction rate due to the large optical depths and progressive return of the UV flux one experiment was performed with activation of the ozone destruction for zenith angles lower than $87^{\circ}$. This influences the timing of ozone destruction in August, but does not influence much the quasi steady state reached at the end 


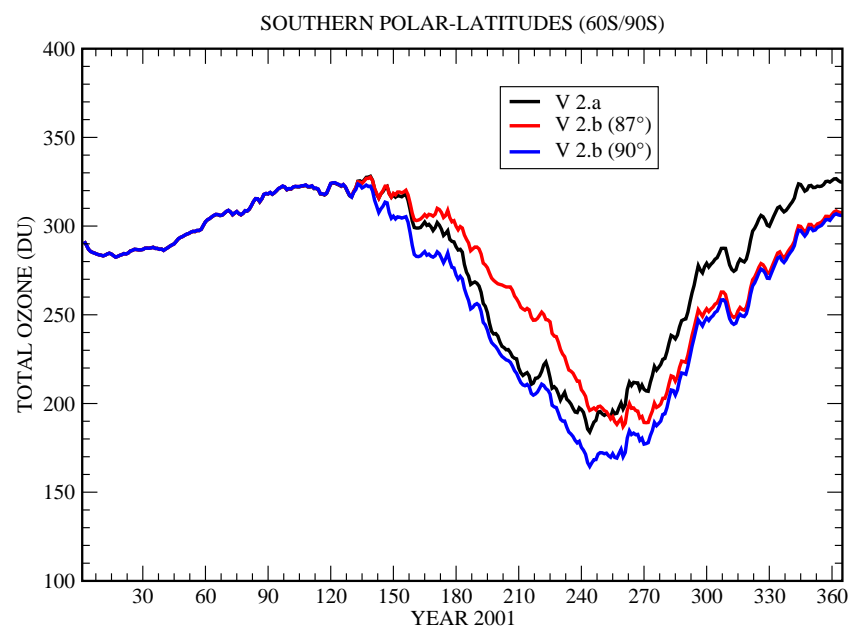

Fig. 12. Evolution of the total ozone columns averaged over the 60$90 \mathrm{~S}$ latitude band for different configurations of the ozone parameterization (black: v2a, red: v2b with activation of the heterogeneous ozone destruction for $\mathrm{SZA}<87^{\circ}$, and blue: v2b with activation of the heterogeneous ozone destruction for $\mathrm{SZA}<90^{\circ}$ ).

of September and the subsequent evolution in October (see Fig. 12).

Examination of the vertical ozone profiles above the Neumayer station (Fig. 13) shows that the depleted ozone layer is distributed between 150 and $20 \mathrm{hPa}$. All the model simulations overestimate the ozone content in the layer 200$100 \mathrm{hPa}$, due to the excessive ozone transport from the midlatitudes prior to the ozone destruction, as discussed above. Compared to the soundings, the model simulations using v $2 \mathrm{~b}$ is in better agreement with observation than the simulation with the v2a version, and is not sensitive to the choice of the zenith angle for activation of the heterogeneous chemistry.

The other noticeable impact on the ozone distribution is found at mid-latitudes in spring and summer. Due to the erosion of the vortex and the possible in-situ ozone destruction within extracted air masses, the southern ozone content is reduced by about 20-25 DU from mid-August to November (not shown). This also brings the model simulation in better agreement with observations.

In the $\mathrm{NH}$, the lower stratosphere vortex is more disturbed and warmer, so the distribution of the tracer shows excursions of air masses with high tracer values at lower latitudes, but with a lower covered area than in the SH (Fig. 14). Tongues of tracer air are also encountered but seem to mix more rapidly. The ozone depletion appears more variable in the NH than in the SH. It depends on the planetary wave activity during winter, the coldness of the air masses inside the vortex, and the date of the final warming. For the year 2001, which encountered a moderate wave activity at the beginning of the winter and a significant warming in mid-February, the ozone amount using $\mathrm{v} 2 \mathrm{~b}$ is reduced by about $20 \mathrm{DU}$ beyond $60^{\circ} \mathrm{N}$ from the end of January to mid-March (Fig. 15).

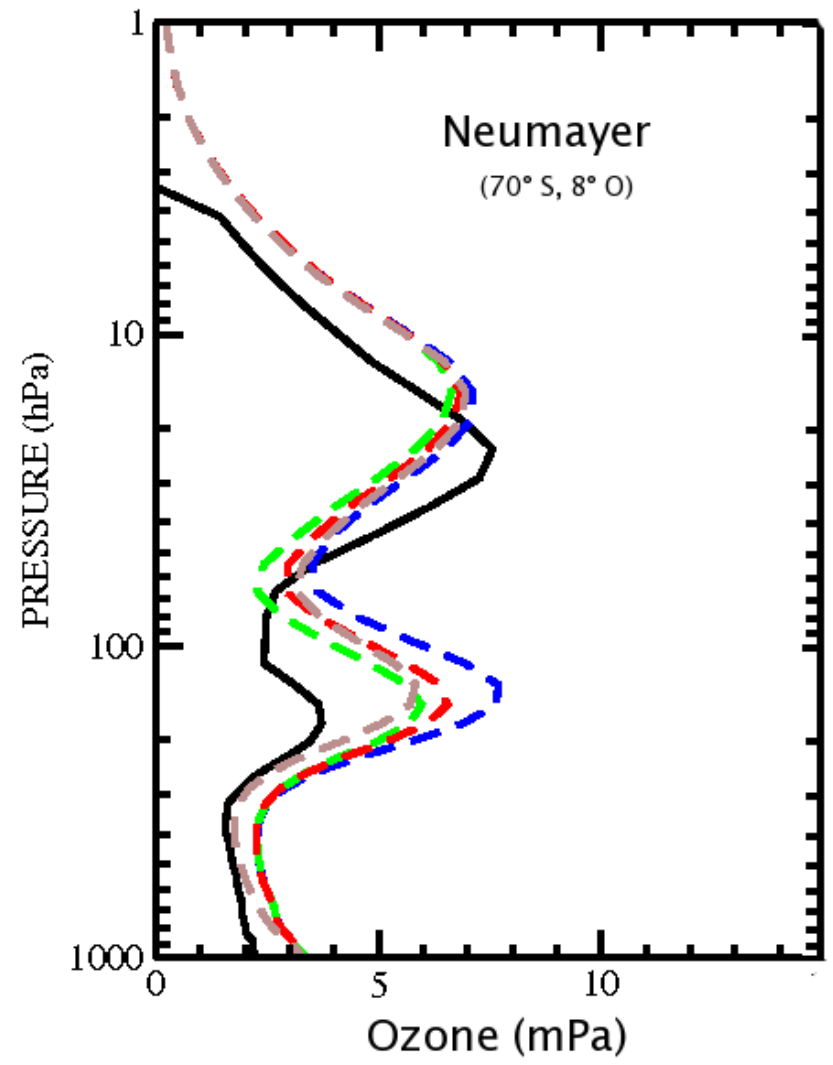

Fig. 13. Ozone vertical profiles over the station of Neumayer. The profiles are averaged over September-October for the soundings (black), the model simulations using v2a (blue), "restricted" v2a (brown), and $\mathrm{v} 2 \mathrm{~b}$ (green and red for activation of polar ozone destruction for SZA lower than $90^{\circ}$ and $87^{\circ}$, respectively).

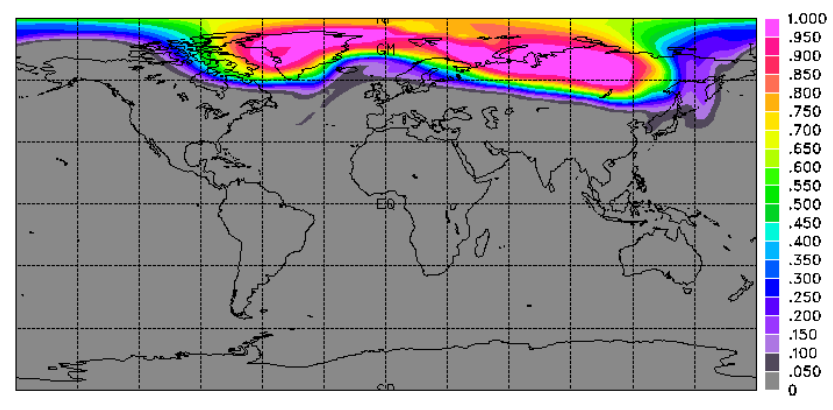

$2001 / 02 / 0100$

$50 \mathrm{hPa}$

Fig. 14. Distribution of the cold tracer for the 1 February 2001.

Thus, with the $\mathrm{v} 2 \mathrm{~b}$ formulation about half of the high-latitude ozone overestimation is removed. This result is not very sensitive to the value of the zenith angle chosen for activation of the heterogeneous ozone destruction. 


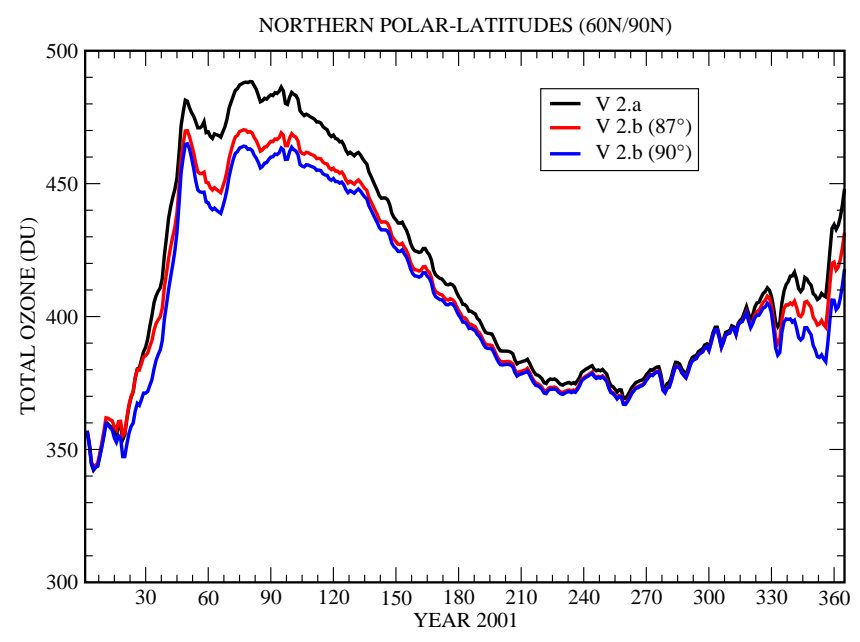

Fig. 15. Evolution of the total ozone columns averaged over the 60$90 \mathrm{~N}$ latitude band for different configurations of the ozone parameterization (black: v2a, red: v2b with activation of the heterogeneous ozone destruction for $\mathrm{SZA}<87^{\circ}$, and blue: v2b with activation of the heterogeneous ozone destruction for $\mathrm{SZA}<90^{\circ}$ ).

\section{Conclusions}

We developed a new version, v2a, of the parameterization used in the original CD86 work. It includes the upgrade of the photochemical model which generated its coefficients, and the implementation of a scheme for the polar ozone destruction that takes into account the local stratospheric temperature and the total chlorine content. Forced by the ECMWF analyses, this version gives satisfactory results with moderate biases in the range $20-40 \mathrm{DU}$ outside the high $\mathrm{NH}$ latitudes, and little drifts compared to the TOMS ozone data. It reproduces well the ozone inter-annual variability connected to the variations of the stratospheric temperature inside the vortices that modulate the rate of the polar ozone destruction.

The v2a version is now included in the latest version of the ARPEGE-Climat model and, since February 2006, in the operational IFS model of the ECMWF. It is thus also used in the variational ozone assimilation system of the ECMWF. The assimilation of ozone data allows additional validation of the parameterization, by the systematic measure of the distances between the observations and the trajectory of the model. Our parameterization works correctly in this framework, as well as in the system developed by the UK Meteorological Office and implemented by the DARC for an intercomparison exercise of simplified ozone schemes (Geer et al., 2007).

The version $\mathrm{v} 2 \mathrm{~b}$ which uses a cold tracer further improves the seasonal evolution of the stratospheric ozone. Notably, the ozone content at mid and high latitudes is reduced due to the increase of the occurrence of the conditions prevailing for ozone destruction, and the export of air masses with lowered ozone contents toward the mid-latitudes. In particular, in the Southern Hemisphere the ozone content inside the polar vortex in autumn is maintained in lower concentrations, in better agreement with the observations. This v $2 \mathrm{~b}$ version is likely to be a very good compromise if one wishes to improve the simulation of the polar processes with an efficient scheme in terms of computing time, avoiding at the same time the introduction of complex heterogeneous atmospheric chemistry. For example, the MOCAGE model with the v2b ozone parameterization uses 20 time less CPU time than required with the full chemical scheme.

The two versions of the parametrization are, generally, more sensitive to the stratospheric temperatures than the CD86 version. This leads to an increased variability of the simulations, so it will be very interesting in the future to estimate their impact in longer simulations. For instance, the ARPEGE-Climat model can be integrated for several decades to evaluate the climatic impact of scenarios including the evolution of the concentration of greenhouse gases and the total stratospheric chlorine content, with a profile consistent with the protocols relative to the limitation of the atmospheric release of chlorofluorocarbons (WMO, 2003). Using the present parameterization should allow one to easily make sensitivity experiments, and possibly to explore a wider range of scenarios, without directly implementing the still very expensive coupling between general circulation ocean/atmosphere coupled models and photochemical models.

Acknowledgements. We thank D. Olivié and R. Paoli for helpful comments on the manuscript. This work was supported by the European Union FP6 Integrated Project QUANTIFY (http://www. pa.op.dlr.de/quantify/). The coefficients of the v2 parameterization can be obtained from the authors (daniel.cariolle@ cerfacs.fr or hubert.teyssedre@meteo.fr).

Edited by: M. Dameris

\section{References}

Andersson, E., Beljaars A., Bidlot J., Miller, M., Simmons, A., and Thepaut, J. N.: A major new cycle of the IFS: cycle 25R4, ECMWF Newsletter 97, ECMWF, Shinfield Park, Reading, Berkshire RG2, 9AX, UK, 2003.

Boering, K. A., Wofsy, S. C., Daube, B. C., Schneider, H. R., Loewenstein, M., Podolske, J. R., and Conway, T. J.: Stratospheric mean ages and transport rates from observations of carbon dioxide and nitrous oxide, Science, 274, 1340-1343, 1996.

Braesicke, P., Hurwitz, M. M., and Pyle, J. A.: The stratospheric response to changes in ozone and carbon dioxide as modelled with a GCM including parameterised ozone chemistry, Meteorol. Z., 15, 343-354, doi:10.1127/0941-2948/2006/0124, 2006.

Bregman, A., Meijer, E., and Scheele, R.: Key aspects of stratospheric tracer modeling using assimilated winds, Atmos. Chem. Phys., 6, 4529-4543, 2006,

http://www.atmos-chem-phys.net/6/4529/2006/.

Cariolle, D. and Brard, B.: The distribution of ozone and active stratospheric species: Result of a two-dimensional atmospheric 
model, in: Atmospheric Ozone, edited by: Zerefos, C. S. and Ghazi, A., pp. 77-81, D. Reidel, higham, Mass., 1984.

Cariolle, D. and Déqué, M.: Southern hemisphere medium-scale waves and total ozone disturbances in a spectral general circulation model, J. Geophys. Res., 91, 10 825-10 846, 1986.

Cariolle, D., Lasserre-Bigory, A., and Royer, J. F.: A general circulation model simulation of the springtime antarctic ozone and its impact on mid-latitudes, J. Geophys. Res., 95, 1883-1898, 1990.

Chipperfield, M.: Multiannual simulations with a three-dimensional chemical transport model, J. Geophys. Res., 104, 1781-1805, 1999.

de Laat, A. T. J., Landgraf, J., Aben, I., Hasekamp, O., and Bregman, B.: Validation of Global Ozone Monitoring Experiment ozone profiles and evaluation of stratospheric transport in a global chemistry transport model, J. Geophys. Res., 112, D05301, doi:10.1029/2005JD006789, 2007.

Dethof, A. and Holm, E.: Ozone assimilation in the ERA-40 reanalysis project, Quart. J. Roy. Meteorol. Soc., 131, 2851-2872, 2004.

Déqué, M., Dreveton, C., Braun, A., and Cariolle, D.: The ARPEGE/IFS atmosphere model: a contribution to the French community climate modelling, Clim. Dyn., 10, 249-266, 1994.

Dunkerton, T.: On the mean meridional mass motions of the stratosphere and mesosphere, J. Atmos. Sci., 53, 2325-2333, 1978.

Eyring, V., Butchart, N., Waugh, D. W., et al.: Assessment of temperature, trace species and ozone in chemistry-climate model simulations of the recent past, J. Geophys. Res., 111, D22308, doi:10.1029/2006JD007327, 2006.

Feng, W., Chipperfield, M. P., Dorf, M., and Pfeilsticker, K.: Midlatitude ozone changes: studies with a 3-D CTM forced by ERA40 analyses, Atmos. Chem. Phys. Discuss., 6, 6695-6722, 2006, http://www.atmos-chem-phys-discuss.net/6/6695/2006/.

Fortuin, J. P. F. and Langematz, U.: An update on the global ozone climatology and on concurrent ozone and temperature trends, Proceedings SPIE, Vol. 2311, Atmospheric Sensing and Modeling, 207-216, 1994.

Geer, A. J., Lahoz, W. A., Jackson, D. R., Cariolle, D., and McCormack, J. P.: Evaluation of linear ozone photochemistry parameterizations in a stratosphere-troposphere data assimilation system, Atmos. Chem. Phys., 7, 939-959, 2007, http://www.atmos-chem-phys.net/7/939/2007/.

Hadjinicolaou, P., Pyle, J. A., Chipperfield, M. P., and Kettleborough, J. A.: Effect of interannual meteorological variability on mid-latitude O-3, Geophys. Res. Lett., 24, 2993-2996, 1997.

Hadjinicolaou, P. and Pyle, J. A.: The impact of Arctic ozone depletion on northern middle latitudes: Interannual variability and dynamical control, J. Atmos. Chem., 47(1), 25-43, 2004.

Hadjinicolaou, P., Pyle, J. A., and Harris, N. R. P.: The recent turnaround in stratospheric ozone over northern middle latitudes: A dynamical modeling perspective, Geophys. Res. Lett., 32, L12821, doi:10.1029/2005GL022476, 2005.

Hofmann, D. J., Oltmans, S. J., Lathrop, J. A., Harris, J. M., and Vemel, H.: Record low ozone at the South Pole in the spring of 1993, Geophys. Res. Lett., 21, 421-424, 1994.

Jrrar, A., Braesicke, P., Hadjinicolaou, P., and Pyle, J. A.: Trend analysis of CTM derived total ozone using self-consistent proxies: How well can we explain dynamically induced trends, Quar. J. R. Meteorol. Soc. , 132, 1969-1983, doi:10.1256/qj.05.136, 2006.
Josse, B., Simon, P., and Peuch, V.-H.: Radon global simulations with the multiscale chemistry and transport model MOCAGE, Tellus, 56B, 339-356, 2004.

Mahfouf, J.-F., Cariolle, D., Royer, J.-F., Geleyn, J.-F., and Timbal, B.: Response of the METEO-FRANCE climate model to changes in $\mathrm{CO} 2$ and sea-surface temperature, Clim. Dyn., 9, 345-362, 1994.

McCormack, J. P., Eckermann, S. D., Siskind, D. E., and McGee, T. J.: CHEM2D-OPP: A new linearized gas-phase ozone photochemistry parameterization for high-altitude NWP and climate models, Atmos. Chem. Phys., 6, 4943-4972, 2006, http://www.atmos-chem-phys.net/6/4943/2006/.

McLinden, C. A., Olsen, S. C., Hannegan, B., Wild, O., Prather, M. J., and Sundet, J.: Stratospheric ozone in 3-D models: A simple chemistry and the cross-tropopause flux, J. Geophys. Res., 105, 14653-14 665, 2000.

Mengistu Tsidu, G., von Clarmann, T., Stiller, G. P., Hopfner, M., Fischer H., Glatthor, N., Grabowski, U., Kellmann, S., Kiefer, M., Linden, A., Milz, M., Steck, T., Wang, D. Y., and Funke, B.: Stratospheric $\mathrm{N}_{2} \mathrm{O}_{5}$ in the austral spring 2002 as retrieved from limb emission spectra recorded by the Michelson Interferometer for Passive Atmospheric Sounding (MIPAS), J. Geophys. Res.,109, D18301, doi:10.1029/2004JD004856, 2004.

Morris, G. A., Gleason, J. F., Russell III, J. M., Schoeberl, M. R., and McCormick, M. P.: A comparison of HALOE V19 with SAGE II V6.00 ozone observations using mapping, J. Geophys. Res., 107(D13), 4177, doi:10.1029/2004GL022131, 2002.

Oikonomou, E. K. and O'Neill, A.: Evaluation of ozone and water vapor fields from the ECMWF reanalysis ERA40 during 1991-1999 in comparison with UARS satellite and MOZAIC aircraft observations, J. Geophys. Res., 111, D14109, doi:10.1029/2004JD005341, 2006.

Prather, M. J.: Numerical advection by conservation of second order moments, J. Geophys. Res., 91, 6671-6681, 1986.

Pyle, J. A., Braesicke, P., and Zeng, G.: Dynamical variability in the modelling of chemistry-climate interactions, Faraday Discuss., 130, 2739, doi:10.1039/b417947c, 2005.

Ricaud, P., Lefèvre, F., Berthet, G., Murtagh, D., Llewellyn, E. J., Mégie, G., Kyrölä, E., Leppelmeier, G. W., Auviven, H., Boonne, C., Brohede, S., Degenstein, D. A., de la Noë, J., Dupuy, E., El Amraoui, L., Eriksson, P., Evans, W. F. J., Frisk, U., Gattinger, R. L., Girod, F., Haley, C. S., Hassinen, S., Hauchecorne, A., Jimenez, C., Kyrö, E., Lautié, N., Le Flochmoën, E., Lloyd, N. D., McConnell, J. C., McDade, I. C., Nordh, L., Olberg, M., Pazmino, A., Petelina, S. V., Sandqvist, A., Seppälä, A., Sioris, B. H., Solheim, B. H., Stegman, J., Strong, K., Taalas, P., Urban, J., von savigny, C., von Scheele, F., and Witt, G.: Polar vortex evolution during the 2002 Antarctic major warming as observed by the Odin satellite, J. Geophys. Res., 110, D05302, doi:10.1029/2004JD005018, 2005.

Simmons, A. J., Hortal, M., Kelly, G., McNally, A., Untch, A., and Uppala, S.: ECMWF analyses and forecasts of stratospheric winter polar vortex breakup: September 2002 in the Southern Hemisphere and related events, J. Atmos. Sci., 62, 668-689, 2005.

Solomon, S.: Stratospheric ozone depletion: A review of concepts and history, Rev. Geophys., 37, 275-316,1999.

WMO (World Meteorological Organization): Scientific Assessment of Ozone depletion: 2002, Global ozone Research and Monitoring Project, Report No. 47, 498 pp., Geneva, 2003. 